\title{
RECENT ADVANCES IN THE CONNSTRUCTION OF FIRE- AND BURGLAR-PROOF SAFES.
}

(Read at Stated Meeting of the Institute, held Wednesday, October 19, 1910.)

BY

MR. E. E. WATSON, Factory Supervisor, Herring-Hall-Marvin Safe Company, Hamilton, Ohio.

[In this article is presented an interesting account of the progress made in lock-making and safe-building during the past century.]

In order to place before you the recent advances in the construction of fire- and burglar-proof safes, it is necessary to cover a brief history of the industry from its actual beginning in the early part of the Nineteenth Century down to the present time.

Practically speaking, the more recent advances have had to do principally with refinements in mechanical processes, the development of factory organization and the perfection of elements. of design that were conceived long before the means were at hand for their proper realization.

The development of any industry is in a large measure dependent upon the activity in other related industries, and the progress in the one must mean a general forward movement on the part of all.

The development of the art of building safes for the protection of valuables is interwoven so closely with that of the art of lock building that the two subjects necessarily must be treated together.

It is a fact that is apparent to anyone who gives consideration to the subject, that a safe, however secure from the stand-point of construction, would be useless without an opening giving free access to its interior, and that opening guarded by a lock at least as secure in point of design and construction as the safe itself.

The conclusion must be drawn from this that safe building, in point of relative security, could only keep pace with the development and with the design and construction of locks. The history, therefore, of the development of the safe building art is in reality, first, the history of the development of locks. 
Locks, as we know them to-day, and as they have been known ever since they were first used, consist primarily of a bolt and a key for operating the bolt, and some means interposed between the key and the bolt to render the operation of the bolt either more or less difficult or impossible without the use of the proper key.

The means employed for housing the working mechanism of the lock, and for applying it to the protected structure, are of little importance in this consideration. All of the different locks possess these features. They may be divided into several general classes.

First, not only in point of simplicity, but naturally also in point of historical origin, is the latch lock, in which there is a bolt pivoted on a fixed point and raised by some sort of a key.

Locks were later rendered more secure by the introduction of the warded type in which the introduction of the key into the hole provided for it was rendered more or less difficult by means of interposed wards, making it, to a degree at least, impossible to introduce the wrong key.

The warded type of lock was succeeded by the present day lever tumbler type, in which tumblers are interposed between the key and the bolt, making it necessary for the key to lift the different tumblers before the bolt can be withdrawn. This type of lock is considered secure in proportion to the number of tumblers used and the means provided for varying the relative amount of lift.

The bolt of this type of lock has fitted to it a member that passes into slots in the lever tumblers in the operation of its withdrawal, and the province of the key is to line up these slots in the lever tumblers so that they register with the fixed member on the bolt.

A later development of the tumbler type of lock is that known as the cylinder pin-tumbler lock. In this type of lock the obstruction consists of divided pins preventing the turning of the plug until these pins have been raised to a point where the division line between the different sets of pins coincides with the outer surface of the plug, and the inner surface of the cylinder, in which it rotates. When these points have been so lined up by the introduction of the proper key the cylinder may be rotated and the bolt withdrawn.

The inconvenience resulting from the use of the ordinary type of key lock, by reason of the fact that keys could be wrongfully 
duplicated, or they might in various ways come into the possession of persons not entitled to them, gave the necessary impetus to inventive genius, and the modern dial or combination lock was the result.

Coincident with the development of the dial lock is that of the changeable type of key lock, in which the arrangement of the tumblers or obstacles may be almost indefinitely varied. It practically, after being set up to a new key, becomes an entirely new lock and cannot be operated by any other key than that to which it is set up.

The development of the changeable-key type of lock is of great importance for the reason that a limited amount of security is frequently needed of a kind that cannot be afforded by the ordinary type of lock. This security is frequently furnished by combination or dial locks that are much more expensive.

The changeable key locks, until recently, have been of a design and construction that were very apt to get out of order and cause considerable inconvenience to the user.

Many efforts have been made to produce a simple lock of the changeable-key type, all of them depending upon the introduction of a double tumbler between the key and the bolt. The changeable-key lock that is being manufactured by the Herring-HallMarvin Safe Co. is the only one in which the obstacle that is interposed consists of a single member. The tumbler of this lock departs from the lever tumbler type previously employed in that it has no fixed pivot but can be properly called a balanced tumbler.

Its greatest merit is its simplicity and its substantial construction. In all other types of changeable-key locks the means provided for changing the combination are delicate, and in the ordinary operation of the lock the wear on these delicate parts is constant. In this lock the means provided for changing the combination are not in the least delicate, and the ordinary operation of the lock in opening and closing after it has been set up to a key causes absolutely no wear on the combination part of the tumbler, making the lock just as substantial, and as little liable to get out of order as the simple lever tumbler type of lock.

It is generally conceded by those who are interested in the manufacture and sale of locks that the changeable-key type of lock has been greatly limited in its use heretofore by reason of its delicacy, and its propensity for getting out of order. 
As an evidence of the simplicity of the Herring-Hall-Marvin Safe Co. lock, it is necessary only to call attention to the fact that in this lock, which admits of over 59,000 different changes, there are but $\mathrm{I} 4$ parts, while in the highest type of changeable-key lock previously invented, which afforded but about 8000 changes, there were over 40 parts.

Its application, while not exactly universal, is broad enough to enable it almost entirely to supplant the other types of key locks.

In the case of apartment houses, where tenants are constantly changing, the ordinary type of lock affords absolutely no security, for the reason that keys may be duplicated. With the changeable-key type of lock it requires but an instant of time to set up the lock to a new key and thereby render all previous keys inoperative.

The combination lock, as it is known to-day to distinguish it from the key lock, became a necessity when it had been demonstrated that practically all key locks could be picked. This fact was developed in the historic lock controversy of $185 \mathrm{I}$, in England, when Mr. Hobbs succeeded in picking all of the best makes of locks.

A few years later, to be exact in $1856, \mathrm{Mr}$. Linus Yale, Jr, succeeded in picking several of the Hobbs locks. It then became generally conceded that no difference what the obstacles were that were interposed between the key and the bolt so long as an opening was left for the insertion of the key, this same opening provided means for the insertion of picks to raise the tumblers. Mr. Yale then turned his attention to the designing of a lock that could be operated in some manner other than by the insertion of a key, and the early type of combination lock was the result.

The combination lock, being in such general use to-day, needs no lengthy description. It consists of the tumblers, the bolt, a lever member interposed between the tumblers and the bolt, and a spindle or arbor, having on its inner end a driving tumbler and on its outer end a dial. The lever member is usually characterized as a fence, and is, from the stand-point of security, a very important part of the combination lock.

The first locks were fitted with a gravity fence, and it was later found that the disc tumblers could be rotated so as to bring their notches in line with the fence even when the combination 
was unknown. The fence rested upon the periphery of the discs and could with patience and a delicate sense of touch, be felt into the notches one at a time until all of the discs were lined up, when the bolt could be retracted by simply turning the dial. This defect was a serious one. It was finally overcome by Mr. Emory Stockwell of the Yale Bank Lock Department, by the invention, in I884, of the balanced fence. This fence was so supported that it brought no weight to bear upon the periphery of the tumblers. It was fitted with a friction bearing and could be moved ont of its neutral balanced position only when the tumblers or discs had all been lined up in registry with it.

This improvement rendered the combination lock absolutely unpickable. It, however, remained for the ingenuity of the burglar to devise ways and means for defeating even this supposedly perfect lock. It was evolved out of the fertile brain of some enemy to organized society, that a mental key always existed and could be secured by torture-the combination numbers were always known by some one. There began, in the year I874, a series of bank robberies all over the United States, the most important of which were carried to a successful termination by reason of this one weakness of the combination lock.

It immediately became evident that a lock with absolutely no communication with the outside of the protected structure was necessary and essential to security, and the invention of the time lock followed. This was and still is, to a large extent, used in connection with the combination lock. Its use prevents the operation of the combination lock until such time as the time lock has run down and, by so doing, withdrawn its obstruction to the operation of the combination locks themselves, or the means pro-. vided for opening.

Meanwhile, in an entirely different field, inventive genius had been equally active by the invention of liquid high explosives, the fluidity of which could be increased by the addition of liquefied ether, so that it could be made to flow into the space surrounding the lock spindles or into the joint between the door and the frame. The burglar, without first securing any proprietary rights in the invention, adopted this method and the battle of wits began over again, with the result that the lock makers finally evolved a motor device working in conjunction with a time lock, which made it unnecessary to connect the outside of the door with the 
inside by means of spindles. The motor after being set would throw the bolts, when the door was seated into the jambs, and would instantly retract them when tripped by the running down of the time lock.

The motor device has not been universally adopted for several reasons, mainly because spindles can be, and are, made so that they cannot be driven in or pulled out, and they can be, and are, made drill-proof. They are ground into the doors so closely that no liquid can be forced around them.

In concluding that part of this paper which relates to locks, I desire to call attention to the fact that while practically all types of key locks can be picked, it does not follow that the key lock should be discarded, for the reason that the measure of security afforded by the lock need not be greater than that afforded by the protected structure itself. Manifestly a light wooden door affords very little security, yet millions of them are fitted with locks. Some with the common warded type, others with the lever and pin-tumbler types-all at least affording a measure of security equal to that of the protected structure itself.

That these locks can be picked is no argument against their use because entrance could be had in nearly all cases in an easier way. The inherent defect in all key locks, other than the changeable key type, lies in the facility with which keys may be wrongfully duplicated and used, rendering such locks of no security whatever.

The fire-proof safe which will protect its contents from destruction and bring them safely through such fires as that following the San Francisco earthquake, the Baltimore fire and the Parker Building fire, is of very modern origin.

No historical evidence exists of the use of safes for protection against fire earlier than about the year 1820 , at which time a portable fire-proof safe was constructed in France. This safe consisted of an outer and an inner metal box with a space between filled with some form of non-conductor. No information is obtainable regarding the details of construction or the materials used. Previous to this the only form of fire protection afforded consisted in vaults built of masonry, which, owing to their cost, were limited in use.

In the year I 826 a fire-proof safe was invented by $\mathrm{J}$. Delano. This safe was made of oaken planks three or four inches in thick- 
ness, which were saturated with salt brine to render them to some degree fire-proof, and were covered on the outside with bands of iron held in place by wrought iron nails. This safe afforded only a moderate amount of fire protection. Many of them were destroyed in the great fire in New York in 1845. A safe of this type is now in the possession of the Herring-Hall-Marvin Safe Co. at its Hamilton factory.

Some time between the years 1829 and $183^{2}$ Jas. Connor, of New York City, constructed an iron box with a filling between the walls composed of plaster of Paris. He used this safe in his own office but made no attempt to patent or manufacture it. In I834 William Marr, of England, patented a safe, the peculiar feature of which consisted of sheets of mica pasted on paper, the space between the mica sheets being filled with burnt clay and powdered charcoal mixed.

In $\mathrm{I} 838$, Chubb, of London, produced a safe in which a series of iron plates were used with intermediate spaces packed with wood ashes.

Coincident with these, various other freak safes were patented and placed upon the market, but none of them seem to have left any impress of their individuality on the development of the safe industry.

The first real safe patented, manufactured and put upon the market as a commodity, was introduced by Daniel Fitzgerald, of New York City, in I834. In this safe the fire-proof composition consisted of plaster of Paris, which was first baked and then reduced to a powder, after which it was mixed with water and mica to the consistency of paste and was poured between the outer and inner walls. This filling was a good fire resistant but its chemical action upon the iron plates composing the walls of the safe was such that it weakened the construction and rendered the safe entirely worthless in a short space of time.

Mr. Fitzgerald early associated himself with Azor Marvin, who founded the Marvin Safe Co. and was long considered one of the heads of the safe industry. This Fitzgerald safe was known as the "Salamander" safe, to distinguish it from the woodlined chest built by Delano.

In I 843 Tann Bros. invented and patented a safe which depended for its fire-proofness upon a filling consisting of ground alum mixed with powdered gypsum. These elements were thor- 
oughly mixed and melted together after which the mixture was pulverized and converted into a coarse powder and used in this form for the filling of the safe. The mixture when subjected to extreme heat would give off water. This safe was known as the Marvin Alum and Plaster Patent, and was exploited for many years.

During this time numerous other dry filled safes were invented and placed upon the market. Various kinds of heatresisting elements were used in the filler, but the safes were not a success on account of the fact that in some instances the steel walls of the safe were corroded by the filler, and in other instances the heat-resisting qualities of the material used was low and many of these safes,-in fact the majority of them,--failed to preserve their contents when subjected to the test of great fires.

The industry was not placed upon a solid and substantial basis until after the modern concrete filling came into use. In 1865, when Jos. L. Hall, of Cincinnati, Ohio, the then President of the Hall's Safe \& Lock Co., patented what was known as Hall's Matchless Concrete Filler, a safe was made that would withstand severe fire tests and would actually improve with age. This filler was composed of cements mixed with certain liquids and contained a large proportion of steam-producing elements in solid form. In addition to its non-combustible and non-conductive qualities, it has the other important advantage of materially strengthening the entire structure. It also improves with age instead of disintegrating in the manner of all other fillers that had previously been used.

The claim is made that when heat is applied to a mixture such as this, the liquid element that is contained within it, not in a liquid form, however, but in what has been characterized as water of crystallization, is upon the application of this heat converted into steam, thereby changing the heat into work and rendering it latent.

The most successful dry fillings previously used depended for their heat-resisting qualities upon this same principle, but were a failure on account of their destructive action on the steel walls of the safes, and for the further reason that they did not add any strength to the structure.

In the event of a fire a safe is apt to be subjected to a fall, sometimes from the upper floor of a building to the basement. 
Its construction must be such that it will withstand this fall without exposing its interior to the destructive action of the flames. In the case of a dry-filled safe the exterior shell of metal is apt to be punctured and the dry filling sifted out, leaving some part of the safe entirely unprotected.

The concrete filling above mentioned strengthens the entire structure and by the test of great fires has proven that this added strength is one of the greatest points in its favor. The concrete filling invented by Jos. L. Hall has been improved upon and is now used exclusively by the Herring-Hall-Marvin Safe Co. in the filling of its entire line of fire-proof safes.

During the development of the industry much thought was expended upon the construction of the framework and jambs of the safe itself. A good grade of cast-iron is used in the jambs of the door and the body of the safe. This is used for the reason that cast-iron will withstand greater heat without warping than bars or plates of steel or iron. The framework of the outer box is made of angles securely welded at the corners. These angles add strength to the jamb casting and prevent its breakage in case of a fall. The outer door-plate performs the same function for the casting which serves as the jambs of the door. Particular attention is directed to this combination of metals.

The cast-iron, which will not warp under great heat, but which is apt to break as the result of a fall.

The steel angle-frames and the door-plate which add the necessary strength to the castings so that they will be able to withstand the shock of a fall.

The fire-proof safe made fifty years ago, and filled with the concrete filling, was a creditable article considering the advances made in related industries. It was not fitted, however, with an angle-hoop and the outer body of the safe was necessarily much weaker than in the safes made to-day. The fit of the doors was less accurate, and the workmanship in general, as might be expected, not approaching to any degree that of to-day.

The safe had many defects. The castings mentioned above were cut away on the hinge side of the door for the lodgment of the hinges. The hinges were made with an interlocking lug or boss that closed in back of the frame. The construction was bad on account of the added metal which tended to conduct heat into the interior of the safe, and the weakening effect which it had 
on the frame on account of the metal that had to be cut out in order to provide space for the hinge.

The recent advances in the construction of fire-proof safes. consist :

First, in the Matter of Patterns for Door and Frame Castings.-These patterns have been revised and reconstructed at large expense with a view to securing a better fit between the door and its frame. Foundry practice has improved to such an extent that castings can now be secured with much less variation in size than formerly. To keep pace with, and to take advantage of, this advance in the art of making castings, it was necessary to reconstruct the patterns. When this was done seven years ago, the tenon and groove and the interlocking-jamb features were incorporated in all of them that had not previously been so constructed. We are now using moulding machines in the making of many of our door and frame castings, which has enabled us to further reduce the limit of variation in the size of the castings themselves and to fit together a door and frame with the smallest possible allowance for variation in size of castings.

Gray iron castings can now be made that will withstand a high degree of heat without warping. In the production of our castings we use those materials which have been determined by experiment to be the best adapted to the production of a casting of uniform size, strength and rigidity.

The effect of the close-fitting door, together with the features of the tenon and groove and interlocking flange, upon the relative fire-proofness of the safe is great. A closely fitted door braces and reinforces the strength of the frame, while a loose-fitting door adds the weight of its overhang to the frame and weakens it in direct proportion to the looseness of the fit.

Second, the Framework. - The old style band hoop or frame has been superseded by the solid welded angle-frame. The front frame supports the jamb casting and provides a fastening for the hinges. This angle is a vast improvement over the old style band or bar frame.

The manner of welding the corners is of the greatest importance. We have found by experiment that the best and strongest results can be obtained only by the hand method of welding. After the angles have been mitred at the corners the edges to be joined are hammered out hot by hand, so that they 
will overlap each other when bent. The actual welding operation is then performed by hand and the strength of a corner so produced has been found by test to equal in nearly all cases the strength of a solid section of the angle itself - a result which we have found impossible to arrive at by any other method.

The outer section of the safe has been strengthened by reinforcing wherever experience has shown such reinforcement to be necessary. At the same time no unnecessary weight has been added. In fact, any weight that does not add proportionately to the strength of the whole structure is a serious detriment in case of a fall. In the modern safe we provide angles and bars between the front and rear frames. The angles are placed at the corners and the bars midway between. These are securely tied to the frames of the safe and provide additional means for fastening and supporting the outer steel wall. This outer steel wall, as well as the inner steel wall, is made heavy enough to properly support and retain the fire-proof composition, and light enough so as not to add any superfluous weight to the safe.

The proper proportioning of the parts relative to each other, and to their various functions, is a matter that has been given the most careful consideration in the development of the modern fire-proof safe.

The doors are hung on malleable iron ball-bearing hinges. These hinges are fastened on the outside. The introduction of the interlocking flange in the rear of the door has made it no longer necessary to mortise them into the door and jambs. The burglar would gain nothing by knocking them off. The ball bearings by their resistance to wear maintain the door in its proper relation to the frame, and provide the additional feature of ease of operation. The outside hinge as now used makes it unnecessary to cut away part of the strength of the frame as was formerly done while the inside hinge was used.

The operation of the bolting mechanism has been simplified by being made more direct. The locks now used on the outer doors are of the combination type. They are protected by steel plates to prevent drilling and the arbors or spindles are shouldered to prevent driving in or pulling out.

An additional device is also provided that will automatically hold the bolts in the locked position in case the lock is in any manner rendered inoperative. 
Those features in their best form are all of comparatively recent origin, and have added much to the value of the protection afforded by the modern safe.

The inner steel doors of fire-proof safes have heretofore been guarded by ordinary key locks. The same is true of the small cash boxes usually found as a part of the cabinet equipment. In the very near future the Herring-Hall-Marvin Safe Co. will equip all of its inner doors and cash boxes with changeable key locks, thereby adding greatly to their security by the facility with which keys may be changed by the user.

A complete line of steel interiors fitted with the most improved modern filing devices will shortly be completed and placed upon the market by this same company. This will be a great advance over the type of interiors now in general use.

To the above-mentioned improvements have been added numerous other minor refinements that result from better mechanical methods, modern factory organization, and thorough inspection.

There has lately been placed upon the market by the HerringHall-Marvin Safe Co. a modern safe fitted with a built-in system of electrical protection. This safe may be connected to a central station system or may be fitted with a local alarm. In appearance it resembles closely the ordinary fire-proof safe and is a marked improvement over the types of electrically protected safes now in use, which depend for their security upon a separate electrical cabinet encasing the safe.

In this new safe the electrical circuits are built into the safe itself. The circuits are so arranged that any attempt to wrongfully gain entrance to the safe by the manipulation of the locks, by drilling, or by any other method, will cause an alarm to ring.

The circuit connecting the safe with the alarm is a closed one and is so arranged that it cannot be tampered with without causing the alarm to ring. The Herring-Hall-Marvin Safe Co. owns and controls the patents covering this type of construction.

The so-called burglar-proof safe or vault has been improved and perfected in many ways in the last ten years.

The development of the burglar-proof safe depended in a large measure upon the development of the steel industry, and to a great extent also upon the development of locks. Until such time as really burglar-proof locks had been perfected no great 
advance could be made in the development of the burglar-proof safe or vault.

The burglar-proof safe of to-day must be drill-proof, it must be fitted with a door that seats so closely into the opening provided for it that no liquid explosives of any kind can be forced between the door and the jamb.

Its bolting mechanism must be of sufficient strength to retain the door in its seat and it must be controlled by locks, the operation of which will leave no opening through the door for the introduction of explosives.

The modern method of arriving at these conditions differs greatly from the attempts that were made years ago. Drillproof steel, as formerly used, consisted either of Franklinite, which was cast or poured between two solid metal walls and allowed to harden in place, or strips of so-called spring steel laid between two retaining plates of soft steel.

The drill-proof steel used in the construction of the modern burglar-proof safe or vault is what is known as five-ply steel. It consists of alternate layers of hard and soft steel rolled and welded together, the result being a plate that will, when tempered, successfully withstand the hardest drill and will yet retain enough tensile strength to resist the crushing and rending effect of modern explosives. This steel was not available in the older types of construction. It is now in general use.

The most recent improvement in burglar-proof construction is the round-door safe, and the round-door bank vault. The.increased closeness of fit that can be made in a round door between the door and jamb, and the possibility of actually grinding the door to its seat, makes this type of construction the highest in existence to-day.

The amount of protection afforded by the lighter forms of construction that were in use fifteen or twenty years ago, is in the light of present-day developments very inadequate. It is only in recent years that the jambs, or the union between the door and the frame have been polished. Earlier than this the machining was roughly done, and if too much opening was left a free use of putty and paint at least made an appearance of a fit.

All this has been changed, and for the past eight or ten years no burglar-proof door has been made by a reputable builder that

Vol. CLXX, No. 1020-33 
does not show the polished metal on the edge of the door and jambs.

There are two general types of construction in use to-day, one being characterized as laminated construction, consisting usually of alternate layers of open-hearth steel and five-ply steel, and the other being what is known as insulated constructions. This latter contains an outer section of cast steel containing in its construction insulating materials in which are embedded drillproof rods or bars, and an inner section of laminated construction.

The intention in this latter construction is to eliminate the danger of burning by the electric arc, by Thermite, or the oxyacetylene flame.

There has been much discussion as to the possible use of these agents by the burglar. It is a fact, however, that long before they were considered in this connection the modern builder of bank vaults had made many experiments and had devised ways and means of overcoming practically all the danger from these sources. Many of the older types of bank vaults, however, are not as well protected in this way as are the recent ones.

The general tendency was up until recent years, to build vaults very light in construction. An eight-inch door was considered a very heavy one. Now doors are built as thick as twenty-eight inches, and one is now in course of construction in the factory of the Herring-Hall-Marvin Safe Co. that will be, when completed, thirty-eight inches thick from the outer face of the door to the inner face of the bolt frame plate. The total thickness over all from the surface of the operating mechanism of the door to the extreme inner surface of the glass door covering the bolt work will be sixty-one inches.

The greatest advances, however, in recent years in burglarproof construction have been the result of the application of upto-date mechanical methods in their production.

Modern drill-proof steel gives absolutely adequate protection against the use of the drill. Steels formerly used and incorporated in the construction of bank vaults were not, however, drill-proof to the extent that this quality exists in the present-day steels. These older types of vaults therefore are not as thoroughly burglar-proof in this sense as are the more modern ones.

When the vault manufacturer succeeded in producing a bank vault that would successfully withstand the use of a drill, he 
found that his vaults were subjected to attack by the use of the wedge in the crack of the door itself. The closeness of the fit of the door did not in any way interfere with the successful use of the wedge.

A system of interlocking jambs was devised which in a measure would prevent the springing of the frame away from the door, and this reinforced by the more recent overlapping flange, which makes it impossible for the burglar to use a wedge on one of these modern doors, has eliminated entirely this source of danger. No owner of a modern bank vault need fear either the drill or the wedge.

The same security exists in reference to lock spindles that are used at the present time. Formerly these were carelessly fitted and openings could be found around them for the introduction of liquid explosives. Now they are so carefully ground into the doors that it is impossible even with pressure to force around them any known liquid explosive.

The same close fit is now also made of the door in its seat. Every modern bank vault entrance is subjected to what is known as the water test, and the door must fit so closely into the jambs that it will resist the passage of water between the door and frame.

The operating mechanism of the bolt work has been greatly improved. Formerly the bolts were operated through a system of levers and bell cranks that were indirect in their action, and were frequently the source of great inconvenience to the user. The modern boltwork is operated through gears and racks, and is so balanced in its action that very little effort is required in locking and unlocking.

The hinges are better adapted to the service expected of them. In all modern vaults the doors swing on hinges fitted with ball and roller bearings of the very best design, workmanship and materials, making a door of many tons weight so easy to operate that a child can swing it in and out, yet so perfectly balanced that it will stand at any point. These bearings are fitted with means of adjustment to compensate for wear.

The pressure mechanism for seating the door into the jambs has been improved in design and construction.

The inner surfaces of the front jambs on all of the best examples of the modern doors are brought to a uniform plane to 
provide a perfect seat for the locking bolt wedges. These wedges have an inclined inner face parallel to the bevelled bearing face of the bolts themselves. These bearing faces are made as broad and large as possible, and the wedges are separately adjusted and fitted under the bolts so that when the door is seated and the locking bolts thrown the holding and retaining power is uniformly distributed throughout the entire system.

The modern means employed for binding the locking boit mechanism to the body of the door consists in tapering or conical bolts running well into the body of the door, each bolt separately fit to its seat, and all binding the bars through which the locking bolts operate firmly and securely to the door This method of fastening and fitting makes the door with its bolting mechanism an indivisable unit; the holding and retaining power equalling the great strength of the solid section of the door itself.

In the older types of construction revolving bolts were used. The fit of the doors was so imperfect that it was feared that the burglar might pass a saw through the crack of the door and saw off the locking bolts.

The structure guarded by the door, or entrance, which in common practice is called the lining, has been strengthened and improved upon in many ways. The modern lining is built up of alternate layers of steel plates. A combination is made of plates of unusual toughness and high tensile strength, with drill-proof plates of five-ply welded iron and steel, all bound together and protected at the outer and inner corners by massive steel angles. The plates of adjoining layers are laid at right angles to each other and the size of the various plates are calculated so as to break joints. The surfaces of all plates are rolled to perfect planes and the edges of plates and angles are ground to a liquid proof fit. The angles at the corners are welded into three-way members that effectually bind the vertical and the top and bottom faces of the lining together.

The steel plates used in the construction of the modern vault will resist the penetration of the best drills. The high tensile plates will successfully resist all explosives, and the ground joints prevent the introduction of liquids.

Steels of the quality in use to-day were not obtainable in the earlier years of the industry. Machinery and machining methods were crude, and factory organization as it exists to-day with its 
team work and all of its multudinous aids to rapid and perfect production was undreamed of.

All the foregoing that relates to improvements in bank vaults applies with equal force to burglar-proof safes. The same highgrade materials are used and the same careful methods applied in the construction of even the smallest burglar-proof chest.

Burglar-proof safes are now made both of the laminated and also of the later solid manganese steel variety that are absolutely impervious to any known method of attack.

Coincident with the modern development of the safe and bank vault industry was that of the profession of the Bank Vault Engineer. The industry owes much of its progress to the work done by the pioneers of this profession William H. Hollar, John M. Mossman, Geo. L. Daman, E. A. Strauss, Frederick W. Holmes, Benjamin F. Tripp and George L. Remington.

The days when might was right have given place to the later days when right is mighty. The safe industry stands ready to protect your valuables not only against fire and the burglar but against organized mob violence as well.

Physico-Chemical Studies of Rubber. F. W. Hinrichsen, (Zeit. Angew. Chem., xxiii, 1345.) - The more recent contributions to the chemistry of rubber are summarized. The author regards the constitution of the hydrocarbon as being definitely settled by the researches of Harries, and refers to the possibility of synthetic production. The determination of the molecular weight of the substance present in the globules of the latex has given results which indicate that this substance is not the comparatively simple compound supposed by Weber, the molecular weight being about 3000 . The rubber is undoubtedly present in the latex as a typical colloid. The recent work on the optical activity of the rubber resins and on vulcanization by sulphur chloride is referred to. The reaction in vulcanization appears to be a true chemical reaction, but in presence of moisture, it is accompanied by the formation of sulphur which is adsorbed by the rubber. The maximum addition of $\mathrm{S}_{2} \mathrm{Cl}_{2}$ is represented by the formula $\left(\mathrm{C}_{10} \mathrm{H}_{16}\right)_{2} \mathrm{~S}_{2} \mathrm{Cl}_{2}$.

Very Sensitive Selenium Cells. F. C. Brown. (Phys. Zeit. $\mathrm{xi}, 48 \mathrm{I}$.)--Selenium cells of great sensitiveness can be prepared by using a mixture of two modifications of selenium, viz., the amorphous variety obtained by dissolving vitreous selenium in potassium cyanide and-precipitating with hydrochloric acid and the red crys- 